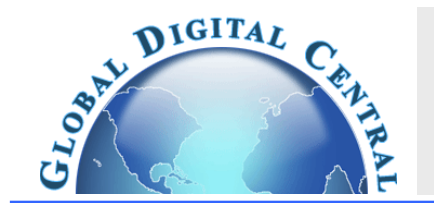

Frontiers in Heat and Mass Transfer

Available at www.ThermalFluidsCentral.org

\title{
NUMERICAL INVESTIGATION AND ANALYSIS OF HEAT TRANSFER ENHANCEMENT IN A MICROCHANNEL USING NANOFLUIDS BY THE LATTICE BOLTZMANN METHOD
}

\author{
Rahouadja Zarita* and Madjid Hachemi \\ Energy and Mechanical Engineering Laboratory, University M.Bougara of Boumerdes, 35000, Algeria
}

\begin{abstract}
In this work, heat transfer enhancement in a microchannel using water-Ag nanofluid has been investigated numerically by the lattice Boltzmann method (LBM) by adopting the stream and collide algorithm, with the (BGK) approximation. The base fluid and the suspended nanoparticles are considered as a homogeneous mixture. And single phase model with first order slip and jump boundary conditions has been adopted. Thermophysical properties of water-Ag nanofluid are estimated by the theoretical models. Effects of change in nanoparticle volume fractions, Reynolds number and Knudsen number are considered. It was concluded that change in nanoparticle volume fractions did not have significant effects on velocity slip. Whereas the temperature jump was significantly influenced. And increasing nanoparticle volume fractions leads to an increase in Nu. However increasing $\mathrm{Kn}$ resulted in less $\mathrm{Nu}$ and a decrease in the skin friction CfRe. The average Nusselt number is enhanced by $12.3 \%$ for a particle volume fraction of $4 \%$ compared with that of pure water at $\mathrm{Re}=3.19$. And the effect of $\mathrm{Re}$ is especially important at higher volume fractions.
\end{abstract}

Keywords: LBM, nanofluids, forced convection, Knudsen number, heat transfer, microchannel.

\section{INTRODUCTION}

Forced convection heat transfer is very essential to engineering designs. In recent years many researchers have been attracted by fluid flow and heat transfer inside the (MEMS) systems Gad-el-Hak (1999). In MEMS devices such as microchannels, the classical boundary conditions based on no-slip boundaries do not hold and should be replaced by the slip and jump boundaries on the walls Asproulis and Drikakis (2010). On the other hand as the scale reduces, Navier-stokes equation could be applied only within the range of Knudsen number Kn, which is defined as the ratio of the molecule mean free path, to a characteristic length scale of the device, $0.001<\mathrm{Kn}<0.1$ for gas flows. Beyond this range the fluid is no longer considered as continuum Rosa et al. (2009), leading to particle numerical methods such as direct simulation of Monte Carlo (DSMC), Molecular dynamic (MD) and the lattice Boltzmann method (LBM).

The LBM has become a computational tool due to its application in many fields including microfluidics Chen and Doolen (1998) and Niu et al. (2007). However in some applications which require high Mach number the LBM falls and it will be more convenient to use more expensive (MD) Kalweit and Drikakis (2008), or multiscale methods Docherty et al. (2014). Many studies were conducted using LB method for studying slip effect in the past decade. Nie et al. (2002) applied the LBM for simulating microchannel flow and micro cavity flow. They showed that the no slip boundary condition can be applied in the continuum limit. However for higher $\mathrm{Kn}$ numbers the continuum assumption does not hold. They concluded that the LBM is a simulation tool for MEMS problems. Lim et al. (2002) investigated the two dimensional isothermal microchannel flow by considering the specular bounce back rule and the extrapolation scheme to produce the slip effect. The results for the pressure variation, slip velocity variation, mass flow rate and average velocity compare well with other results found in the literature. Shen et al. (2004) studied and compared the results obtained by the LBM with those obtained by DSMC. It was concluded that the results obtained by the LBM in the slip regime are in good agreement with those obtained by DSMC method. However for $\mathrm{Kn}=0.388$ which is in the transition regime, the results obtained by the LBM do not match those obtained by the DSMC. Zhang et al. (2005) obtained numerical results with (LBM) simulation for gas flows in microchannels, they derived an expression for the Knudsen number and captured the Knudsen minimum phenomenon. Shu et al. (2005) presented a thermal LB model for simulating microflows. The slip and jump boundary conditions were adopted, they gave a new expression for the relaxation parameter. The results found agree with those of (DSMC) and (MD) methods. Zheng et al. (2007) presented a new model for the velocity and the temperature jump. They showed the effect of Knudsen number on slip and jump boundaries, especially when $\mathrm{Kn}>0.01$. Guo et al. (2009) proposed a microscale flow model for binary mixtures based on the multi-relaxation operator (MRT), their results match well with the results obtained by analytical results. Chai et al. (2011) studied theoretically the slip effect on a porous media composed by a square array arrangement of circular cylinders. They concluded that the study is important especially for air filtration problems. Tian et al. (2007) simulated micro-couette flow with viscous dissipation in the slip regime, by adopting the Maxwell slip model. The results indicated that LBM is an efficient tool for micro flow simulations. Li et al. (2011) presented a new model based on an effective viscosity, to study microchannel flows in the transition regime by using the MRT model. Their results match those of DSMC method for a large Knudsen number variation in the transition regime. 
Shokouhmand and Maghdadi (2011) modified the relaxation parameter in LBM, by taking into account the change in the viscosity and thermal conductivity due to the rarefaction effect. They found that their results for the Nusselt number agree with other results for $\mathrm{Kn} \leqslant 0.2$.

Nanofluids show higher thermal properties as compared to the usual fluids Chol (1995). Scientists and researchers have attached great importance to this new generation of fluids. In fact, they carried out many theoretical Mukherjee et al. (2018), experimental and numerical studies on nanofluids such as thermophysical properties, stability, clogging problems, sedimentation and energy efficiency Mahdy and Chamkha (2015). Previous studies in the macroscale and microscale level for nanofluids have shown the importance of such fluids, in the enhancement of the heat transfer of traditional fluids. Thus all research investigations were concentrated on the understanding and explanation of this augmentation of heat transfer coefficient. It has been concluded that this enhancement is not only due to thermal conductivity effect but other effects are also responsible, such as inertia, Brownian motion, thermophoresis diffusiophoresis, Magnus effect, fluid drainage, and gravity Buongiorno (2006). These are slip effects, which mean there is a relative velocity between fluid particles and solid nanoparticles. It was concluded that, only Brownian diffusion and thermophoresis are important slip mechanisms in nanofluids. Based on this, the nanofluid flow can be modeled by considering a two-component nonhomogeneous equilibrium model for mass, momentum, and heat transport. It was also found that the different slip mechanisms between nanoparticle and the base fluid are dependent on several factors such as the shape, size, and volume fraction of the particles Savithiri et al. (2011). In the present work, homogeneous mixture of Ag-water nanofluid with thermodynamic equilibrium between fluid and solid nanoparticles is considered. The effect of thermal conductivity is approximated by the Maxwell Garnetts model which is for spherical solid particles. The effect of change in nanoparticle volume fractions, Knudsen number $\mathrm{Kn}$ with $\mathrm{Kn} \leqslant 0.1$ and Reynolds number is also considered.

\section{THERMAL LB MODEL}

The thermal LB model presented in this paper uses two different distribution functions for flow and temperature $f_{i}$ and $g_{i}$, respectively.

The governing equations for flow and temperature are taken from Zarita and Hachemi (2014) and are given as follows:

$$
\begin{aligned}
& f_{i}\left(X+c_{i} \Delta t, t+\Delta t\right)-f_{i}(X, t)=-\frac{1}{\tau_{f}}\left[f_{i}(X, t)-f_{i}^{e q}(X, t)\right] \\
& g_{i}\left(X+c_{i} \Delta t, t+\Delta t\right)-g_{i}(X, t)=-\frac{1}{\tau_{g}}\left[g_{i}(X, t)-g_{i}^{e q}(X, t)\right]
\end{aligned}
$$

Where, $\Delta x$ and $\Delta t$ are the lattice grid spacing and the time step and $\tau_{f}, \tau_{g}$ are the momentum and internal energy relaxation time, respectively. The discrete velocities for the D2Q9 model Fig. 1 are given by: $c_{i}=(0,0)$

$c_{i}=\left[\cos \frac{(i-1) \pi}{2}, \sin \frac{(i-1) \pi}{2}\right] c$ $(i=0)$

$c_{i}=\left[\cos \frac{(i-1) \pi}{2}, \sin \frac{(i-1) \pi}{2}\right] c$
The equilibrium distributions $f_{i}^{e q}$ and $g_{i}^{e q}$ for a square lattice and D2Q9 model for flow and temperature respectively are taken from Tian et al. (2007) are given by:

$$
\begin{aligned}
& f_{i}^{e q}=\omega_{i} \rho\left[1+\frac{3\left(c_{i} \cdot u\right)}{c^{2}}+\frac{9\left(c_{i} \cdot u\right)^{2}}{2 c^{4}}-\frac{3(u \cdot u)}{2 c^{2}}\right] \\
& g_{0}^{e q}=-\omega_{0} \rho \varepsilon \frac{3(u \cdot u)}{2 c^{2}} \\
& g_{1,2,3,4}^{e q}=\omega_{1,2,3,4} \rho \varepsilon\left[1.5+\frac{3\left(c_{i} \cdot u\right)}{2 c^{2}}+\frac{9\left(c_{i} \cdot u\right)^{2}}{2 c^{4}}-\frac{3(u \cdot u)}{2 c^{2}}\right] \\
& g^{e q} q_{5,6,7,8}=\omega_{5,6,7,8} \rho \varepsilon\left[3+\frac{6\left(c_{i} \cdot u\right)}{c^{2}}+\frac{9\left(c_{i} \cdot u\right)^{2}}{2 c^{4}}-\frac{3(u \cdot u)}{2 c^{2}}\right]
\end{aligned}
$$

Where the weight factors for a D2Q9 model are: $\omega_{0}=4 / 9$, $\omega_{1,2,3,4}=1 / 9, \omega_{5,6,7,8}=1 / 36$ and $\mathrm{c}$ is defined as: $\quad c=\Delta x / \Delta t=\Delta y / \Delta t$

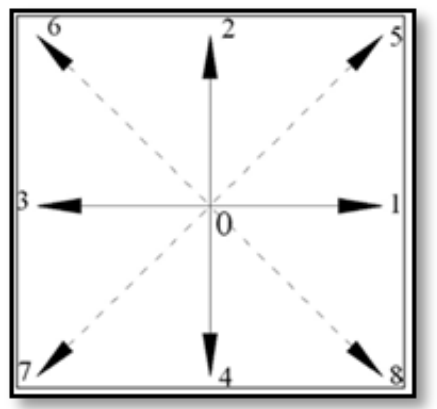

Fig. 1 D2Q9 lattice mode

After computation of distribution functions of Equation 1 and Equation 2 in the so called collision step and streaming step, the macroscopic variables such as density $\rho$, velocity $u$, temperature $\mathrm{T}$ and pressure $\mathrm{P}$ can be calculated in terms of these distribution functions as follows:

$$
\begin{aligned}
& \rho u=\sum_{i} f_{i} c_{i} \\
& \rho=\sum_{i} f_{i} \\
& \rho \varepsilon=\rho R T=\sum_{i} g_{i} \\
& P=\rho C_{S}^{2}
\end{aligned}
$$

The corresponding kinematic viscosity $v$ and thermal diffusivity $\alpha$ are taken from Zarita and Hachemi (2014) and given by:

$v=\left(\tau_{f}-0.5\right) c_{s}^{2} \Delta t$

$\alpha=\left(\tau_{g}-0.5\right) c_{S}^{2} \Delta t$

Where $c_{s}^{2}=R T=c^{2} / 3$ is the speed of sound. 


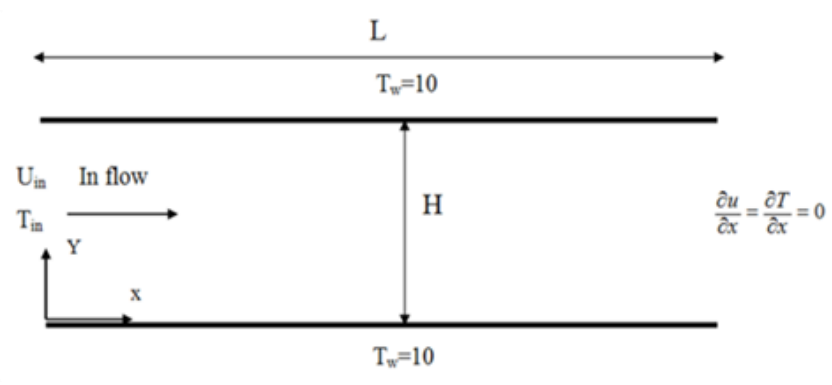

Fig. 2 Geometrical configuration.

\section{NANOFLUID}

The effective density for a homogeneous mixture of the base fluid and solid particles can be calculated as:

$\rho_{n f}=\varphi \rho_{s}+(1-\varphi) \rho_{f}$

In Equation $12 \varphi$ is the nanoparticle concentration and $f, s$ and $n f$ are subscripts which refer to base fluid, solid nanoparticles and nanofluid respectively. The heat capacitance is expressed as:

$\left(\rho C_{p}\right)_{n f}=\varphi\left(\rho C_{p}\right)_{s}+(1-\varphi)\left(\rho C_{p}\right)_{f}$

The thermal diffusivity of the nanofluid can be obtained by Khanafer, Vafai and Lightstone (2003).

$\alpha_{n f}=k_{n f} /\left(\rho C_{p}\right)_{n f}$

The effective viscosity used in this paper is expressed as the Brinkman model Khanafer, Vafai and Lightstone (2003) as:

$\mu_{n f}=\mu_{f} /(1-\varphi)^{2.5}$

For spherical nanoparticles, the effective thermal conductivity can be approximated and calculated by the Maxwell Garnetts model as in Khanafer, Vafai and Lightstone (2003).

$\frac{k_{n f}}{k_{f}}=\frac{k_{s}+2 k_{f}-2 \varphi\left(k_{f}-k_{s}\right)}{k_{s}+2 k_{f}+\varphi\left(k_{f}-k_{s}\right)}$

Table 1 Thermophysical properties of $\mathrm{Ag}$ and water at $20^{\circ} \mathrm{C}$ Kreith et al. (2011)

\begin{tabular}{|c|c|c|c|c|}
\hline & $\mathrm{Cp}(\mathrm{J} / \mathrm{Kg} . \mathrm{K})$ & $\rho\left(\mathrm{Kg} / \mathrm{m}^{3}\right)$ & $\mathrm{K}\left(\mathrm{W} / \mathrm{m} \cdot{ }^{\circ} \mathrm{C}\right)$ & $\begin{array}{l}\mu(\text { Pas }) \times \\
10^{-3}\end{array}$ \\
\hline Water & 4181.8 & 998.2 & 0.593 & 1.002 \\
\hline Ag & 235 & 10500 & 429 & \\
\hline
\end{tabular}

\section{BOUNDARY CONDITIONS}

The following slip (jump) boundary condition is defined as in Zarita and Hachemi (2014).

$$
\begin{aligned}
& u^{\text {slip }}=\sigma \lambda\left(\frac{\partial u}{\partial y}\right)_{w} \\
& T^{j u m p}=\phi\left(\frac{2 \gamma}{\gamma+1}\right)\left(\frac{\lambda}{p_{r}}\right)\left(\frac{\partial T}{\partial y}\right)_{w}
\end{aligned}
$$

Where $\gamma$ and $P_{r}$ are the specific heat ratio and Prandtl number respectively, $\sigma=\left(2-\sigma_{v}\right) / \sigma_{v}$ and $\phi=\left(2-\sigma_{T}\right) / \sigma_{T}$.

Where $\sigma_{v}$ and $\sigma_{T}$ are the tangential momentum accommodation and the thermal accommodation coefficients respectively, these two coefficients are taken equal to 1 .

\subsection{Flow boundary conditions}

The inlet density and the unknown distribution functions at the inlet of the microchannel are calculated based on the work of Zou and $\mathrm{He}$ (1997) as:

$\rho_{\text {in }}=\frac{1}{1-u_{\text {in }}}\left[f_{0}+f_{2}+f_{4}+2\left(f_{3}+f_{6}+f_{7}\right)\right]$

$f_{1}=f_{3}+\frac{2}{3} \rho_{i n} u_{i n}$

$f_{5}=f_{7}-\frac{1}{2}\left(f_{2}-f_{4}\right)+\frac{1}{6} \rho_{i n} u_{i n}$

$f_{8}=f_{6}+\frac{1}{2}\left(f_{2}-f_{4}\right)+\frac{1}{6} \rho_{i n} u_{i n}$

The outlet velocity is not known here. And the normal practice is to use extrapolation for calculating the unknown distribution functions Mohamad (2011). The slip boundary condition for bottom wall is as follows:

$$
\begin{aligned}
& \rho_{w}=f_{0}+f_{1}+f_{2}+2\left(f_{7}+f_{4}+f_{8}\right) \\
& f_{2}=f_{4} \\
& f_{5}=\frac{\rho_{w}\left(1+u_{x}\right)-\left(f_{0}+f_{2}+f_{4}\right)}{2}-\left(f_{1}+f_{8}\right) \\
& f_{6}=\frac{\rho_{w\left(1-u_{x}\right)-\left(f_{0}+f_{2}+f_{4}\right)}}{2}-\left(f 3+f_{7}\right) \\
& u_{x}=\lambda \frac{\left(4 u_{x, 1}-u_{x, 2}\right)}{2+3 \lambda}
\end{aligned}
$$

Where $u_{x, 1}$ and $u_{x, 2}$ are the first two velocity values after the fluid velocity on the wall and $\lambda=K_{n} . m$. With $m$ the total number of lattice nodes in the vertical direction. The slip boundary condition for the top wall is as follows:

$\rho_{w}=f_{0}+f_{1}+f_{3}+2\left(f_{2}+f_{5}+f_{6}\right)$

$f_{4}=f_{2}$ 


$$
\begin{aligned}
& f_{7}=\frac{\rho_{w\left(1-u_{x}\right)-\left(f_{0}+f_{2}+f_{4}\right)}}{2}-\left(f_{3}+f_{6}\right) \\
& f_{8}=\frac{\rho_{w\left(1+u_{x}\right)-\left(f_{0}+f_{2}+f_{4}\right)}}{2}-\left(f_{1}+f_{5}\right) \\
& u_{x}=\lambda \frac{\left(4 u_{x, H-1}-u_{x, H-2}\right)}{2+3 \lambda}
\end{aligned}
$$

\subsection{Temperature boundary conditions}

The temperature boundary condition is implemented using the equality of non-equilibrium distribution functions $g=g^{e q}+g^{n e q}$, as presented in Mohamad (2011). The equation set below is derived for inlet the boundary.

$g_{1}=\frac{1}{9} T_{i n}\left(3+6 u_{x}^{2}\right)-g_{3}$

$g_{5}=\frac{1}{36} T_{i n}\left(6+6 u_{x}^{2}\right)-g_{7}$

$g_{8}=\frac{1}{36} T_{i n}\left(6+6 u_{x}^{2}\right)-g_{6}$

The outlet boundary condition for temperature can be implemented by using an extrapolation scheme for calculating the unknown distribution functions as presented in Mohamad (2011), equations of temperature jump for bottom wall are as follows:

$T_{y=0}=\frac{C_{\text {jump }}\left(4 T_{1}-T_{2}\right)+2 T_{w}}{\left(2+3 C_{\text {jump }}\right)}$

$g_{2}=1.5 T_{y=0}(\omega(2)+\omega(4))-g_{4}$

$g_{5}=3 T_{y=0}(\omega(5)+\omega(7))-g 7$

$g_{6}=3 T_{y=0}(\omega(6)+\omega(8))-g 8$

Where $C_{\text {jump }}$ is the temperature jump coefficient defined according to Equation 18 as:

$C_{j u m p}=B \lambda=\phi\left(\frac{2 \gamma}{(\gamma+1) p_{r}}\right) \lambda=B K n \cdot H$

As can be seen from Equation 40, the temperature jump coefficient depends on the variation of the parameter B and on the Knudsen number. In this work simulations are performed for a constant value of $\mathrm{B}=1.667$. And for different values of Knudsen number.

Equations of temperature jump for top wall are as follows:

$T y=H=\frac{\operatorname{Cjump}\left(4 T_{H-1}-T_{H-2}\right)+2 T_{w}}{(2+3 \operatorname{Cjump})}$

$g_{4}=1.5 T_{y=H}(\omega(2)+\omega(4))-g_{2}$

$$
\begin{aligned}
& g_{7}=3 T_{y=H}(\omega(5)+\omega(7))-g_{5} \\
& g_{8}=3 T_{y=H}(\omega(6)+\omega(8))-g_{6}
\end{aligned}
$$

\section{NON DIMENSIONAL PARAMETERS CALCULATION}

The local Nusselt number is calculated as follows:

$N u(x)=\left.\frac{k_{n f} 2 H}{k_{f}\left(T_{w}-T_{b u l k}\right)} \frac{\partial T}{\partial y}\right|_{w}$

The local friction coefficient is calculated as follows:

$C_{f}(x)=\left.\frac{\mu_{n f}(\partial u / \partial y)}{(1 / 2) \rho_{n f} u_{b u l k}^{2}}\right|_{w}$

Where the bulk temperature at a cross section is calculated as follows:

$$
T_{b u l k}=\frac{\int_{S} \rho v T d S}{\int_{S} \rho v d S}
$$

The average Nusselt number is calculated as follows:

Nuavg $=\frac{\int_{0}^{L} N u(x) d x}{L}$

\section{RESULTS AND DISCUSSIONS}

In this numerical investigation, simulations are performed using the lattice Boltzmann method. The fluid flow between two parallel plates has been considered. The plates are at rest and kept at a constant temperature $\mathrm{Tt}=\mathrm{Tb}=10 \mathrm{Tin}$ and $\mathrm{Tin}=1$, by a laminar flow of forced convection heat transfer of water-Ag nanofluid, with a constant inlet velocity profile.

\subsection{Mesh independency study}

Table 2 and table 3 show the mesh independency study for water-Ag nanofluid for $\varphi=0$ and $\varphi=0.04$ respectively at $\mathrm{Kn}=0.05, \mathrm{Re}=6$. Table 4 shows a mesh independency study at a point $\mathrm{x}=0.03 \mathrm{~L}, \mathrm{y}=0.5$ for $\mathrm{Kn}=0.05$ at $\mathrm{Re}=6$. The mesh of $160 \times 40$ has been selected for the present numerical investigation. 
Table 2 Mesh independency study for water-Ag nanofluid for $\mathrm{Kn}=0.05, \varphi=0$ at $\mathrm{Re}=6$.

\begin{tabular}{lccc}
\hline & $\mathbf{1 4 0 \times 3 5}$ & $\mathbf{1 6 0 \times 4 0}$ & $\mathbf{1 8 0 \times 4 5}$ \\
$\mathrm{Nu}$ & 6.91 & 6.95 & 6.98 \\
$\mathrm{CfRe}$ & 20.49 & 20.47 & 20.45 \\
\hline
\end{tabular}

Table 3 Mesh independency study for water-Ag nanofluid for $\mathrm{Kn}=0.05, \varphi=0.04$ at $\mathrm{Re}=6$.

\begin{tabular}{lccc}
\hline & $\mathbf{1 4 0 \times 3 5}$ & $\mathbf{1 6 0 \times 4 0}$ & $\mathbf{1 8 0 \times 4 5}$ \\
\hline $\mathrm{Nu}$ & 7.62 & 7.65 & 7.68 \\
$\mathrm{CfRe}$ & 20.49 & 20.47 & 20.45 \\
\hline
\end{tabular}

Table 4 Mesh independency study for water- Ag nanofluid at a point $\mathrm{x}=0.03 \mathrm{~L}, \mathrm{y}=0.5$, for $\mathrm{Kn}=0.05, \varphi=0.04, \mathrm{Re}=6$.

\begin{tabular}{lccc}
\hline & $\mathbf{1 4 0 \times 3 5}$ & $\mathbf{1 6 0 \times 4 0}$ & $\mathbf{1 8 0 \times 4 5}$ \\
\hline $\boldsymbol{u} / \boldsymbol{U}_{\text {in }}$ & 1.04 & 1.03 & 1.03 \\
$\boldsymbol{T} / \boldsymbol{T}_{\text {in }}$ & 1.13 & 1.09 & 1.07 \\
\hline
\end{tabular}

\subsection{Numerical validation}

To check the accuracy of the present boundary conditions, velocity and temperature profiles at different cross sections for $\mathrm{Kn}=0.015, \mathrm{Re}=0.01$ and $\operatorname{Pr}=0.7$ are presented in Fig. 3 and compared with the results presented in Niu et al (2007). In Table 5 results for CfRe and $\mathrm{Nu}$ values for different Knin are compared with those presented in Shu et al. (2005) and Kavehpour et al. (1997).

Table 5 Comparison of CfRe and $\mathrm{Nu}$ at the outlet of the microchannel

\begin{tabular}{|c|c|c|c|}
\hline $\mathbf{K} \mathbf{n}_{\text {in }}$ & 0.015 & 0.03 & 0.046 \\
\hline CfRe Kavehpour et al. (1997) & 21.9 & 20 & 18 \\
\hline CfRe Shu et al. (2005) & 21.69 & 19.81 & 18.11 \\
\hline$C f R e$ (present) & 21.97 & 20.27 & 18.74 \\
\hline$N u$ Kavehpour et al. (1997) & 7.4 & 7.0 & 6.60 \\
\hline Nu Shu et al. (2005) & $\begin{array}{l}7.48 \\
7.37\end{array}$ & $\begin{array}{l}7.07 \\
6.87\end{array}$ & $\begin{array}{l}6.63 \\
6.40\end{array}$ \\
\hline$N u$ (present) & & & \\
\hline
\end{tabular}




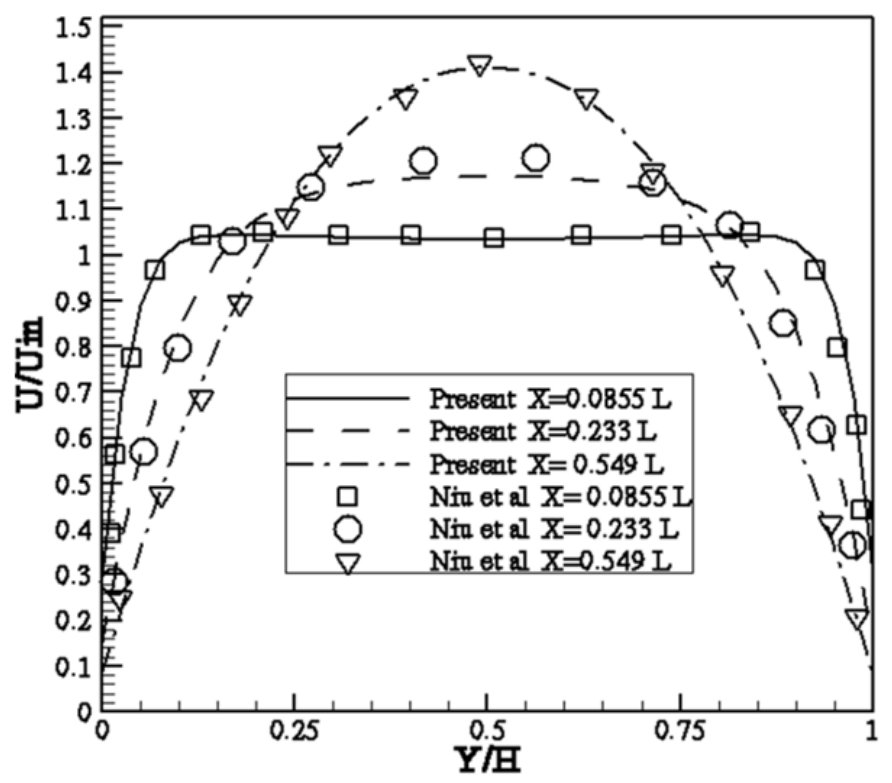

(a)

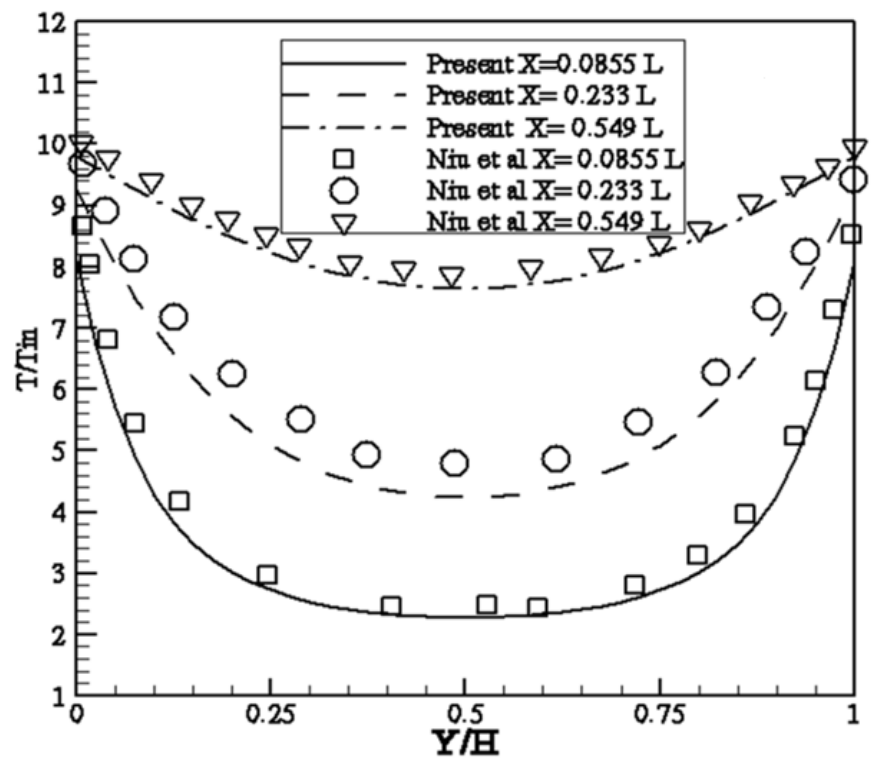

(b)

Fig. 3 Comparison of velocity (a) and temperature (b) profiles at different cross sections with the results presented in Niu et al. (2007) for, $\mathrm{Kn}=0.015, \mathrm{Re}=0.01$ and $\mathrm{Pr}=0.7$.

\subsection{Numerical results and analysis}

Fig. 4 shows the velocity slip and temperature jump variations by comparing velocity and temperature profiles for $\mathrm{Kn}=0.015-0.05, \varphi=0$ at $\mathrm{Re}=3.19$, which corresponds to pure water case. In Fig. 5 are presented the results for velocity slip and temperature jump variations for different Knudsen number. As can be seen from this figure, increasing Kn number leads to increase in slip velocities and decrease in temperature jump in the developing region. Fig. 6 shows the effect of Knudsen number on the skin friction coefficient and on the Nusselt number. It can be seen that increasing Kn number leads to increase in slip velocities which reduces the velocity gradient at the wall. Consequently increasing $\mathrm{Kn}$ reduces the skin friction coefficient CfRe. However, increasing $\mathrm{Kn}$ number leads to decrease in local Nusselt number values for the thermally developing microchannel. The effect of $\mathrm{Kn}$ number on the velocity slip and the temperature jump for water-Ag nanofluid by comparing velocity and temperature profiles along the microchannel for $\mathrm{Kn}=0.015-0.05$ and $\varphi=0.04$ at $\mathrm{Re}=3.19$ is shown in Fig. 7. 


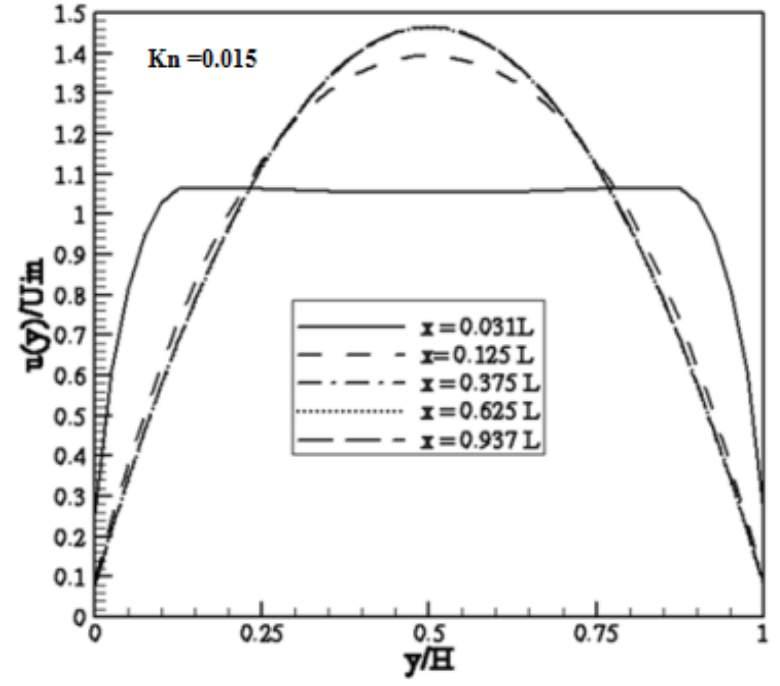

(a)

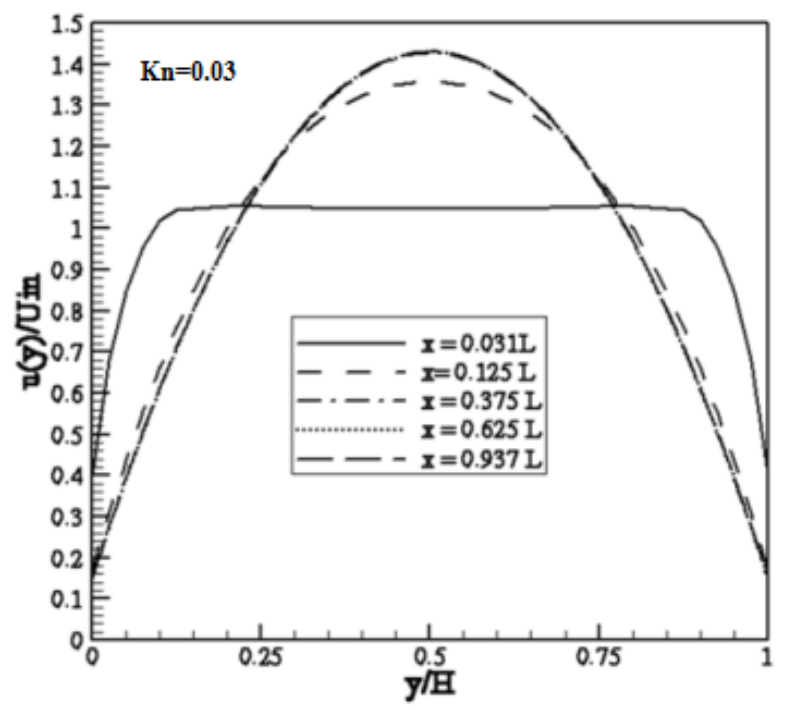

(a)

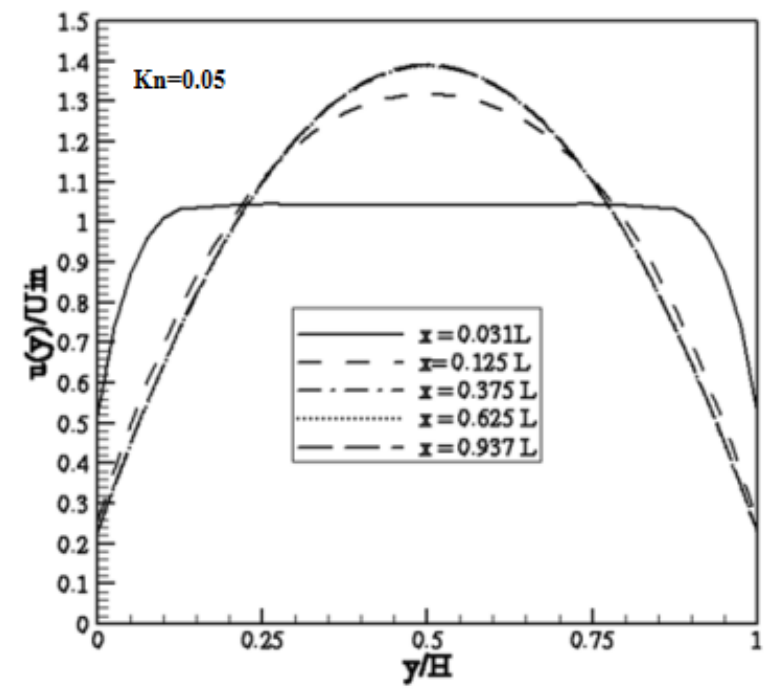

(a)

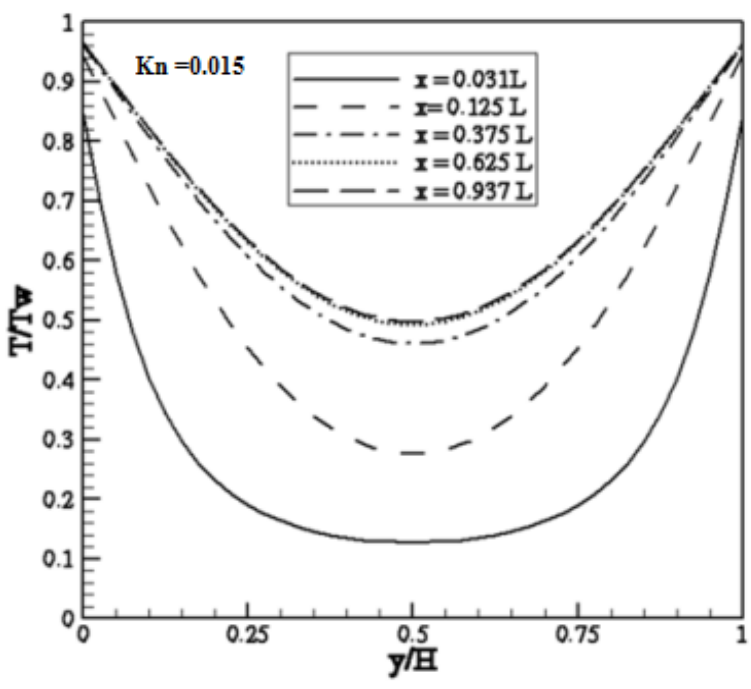

(b)

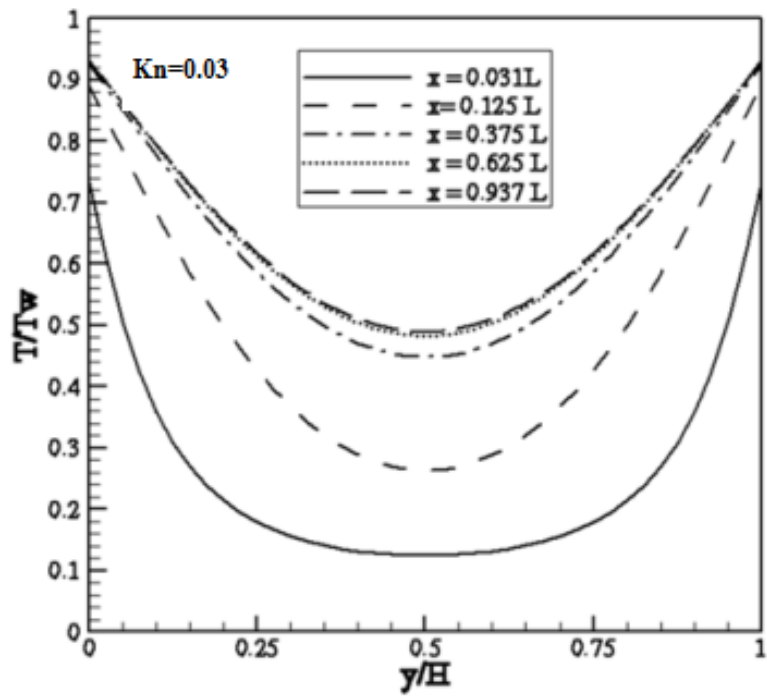

(b)

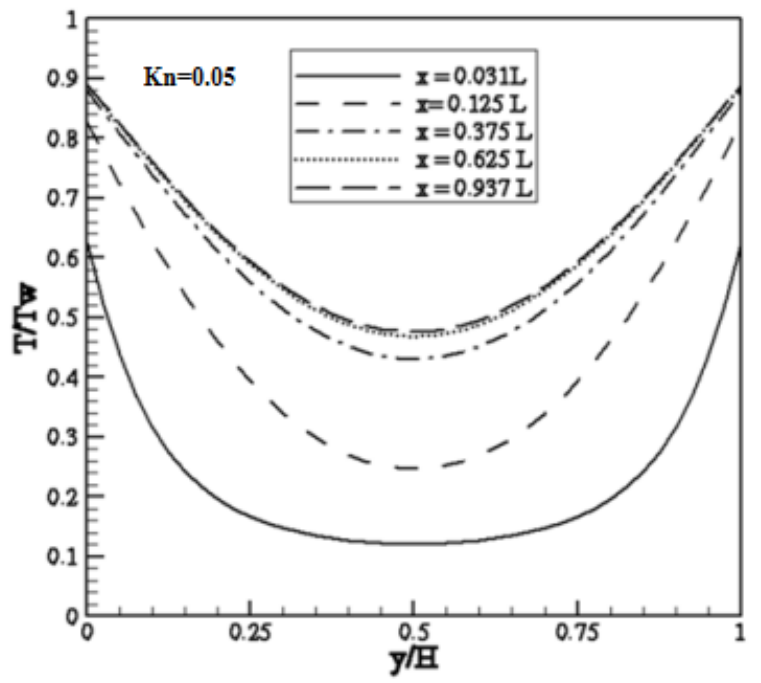

(b)

Fig. 4 Velocity (a) and temperature profiles (b) along the microchannel at different $\operatorname{Kn}$ number $\varphi=0, \operatorname{Pr}=7.06$ at $\operatorname{Re}=3.19$. 


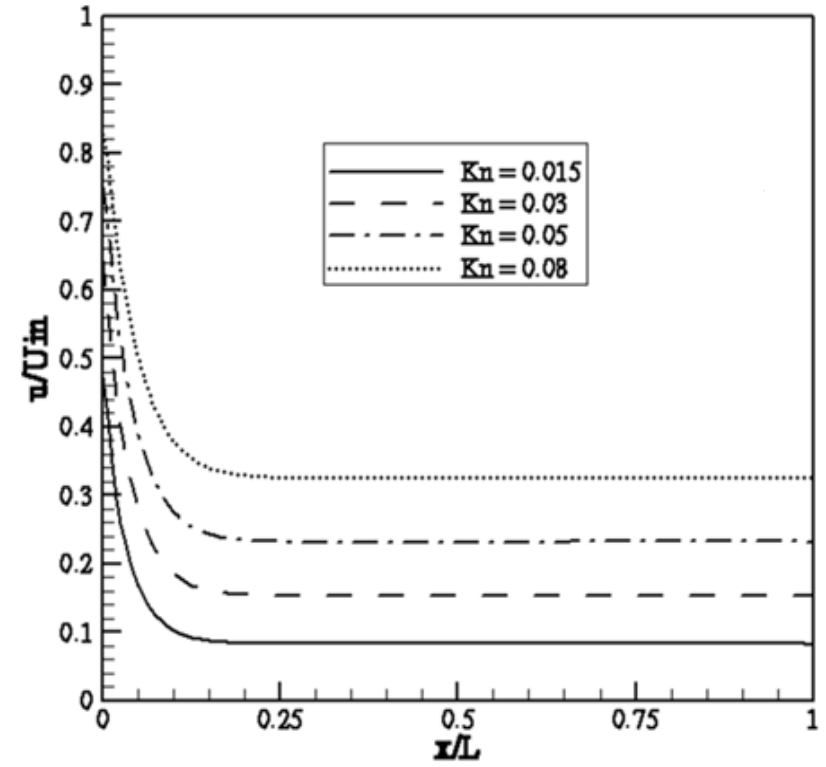

(a)

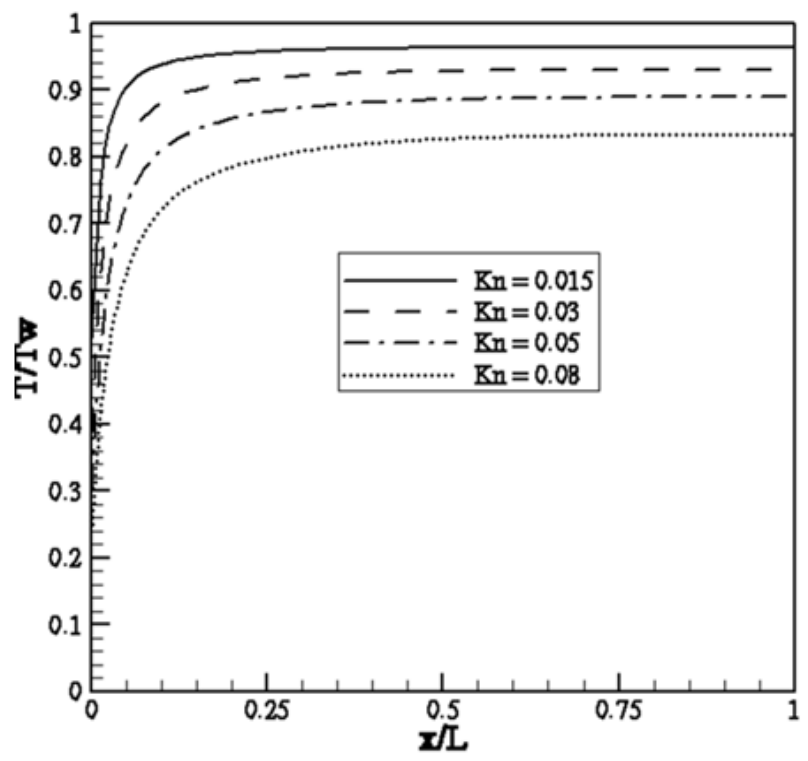

(b)

Fig. 5 Effect of Kn number variation on the velocity slip (a) and temperature jump(b) along the microchannel $\varphi=0, \operatorname{Pr}=7.06$ at $\operatorname{Re}=3.19$.

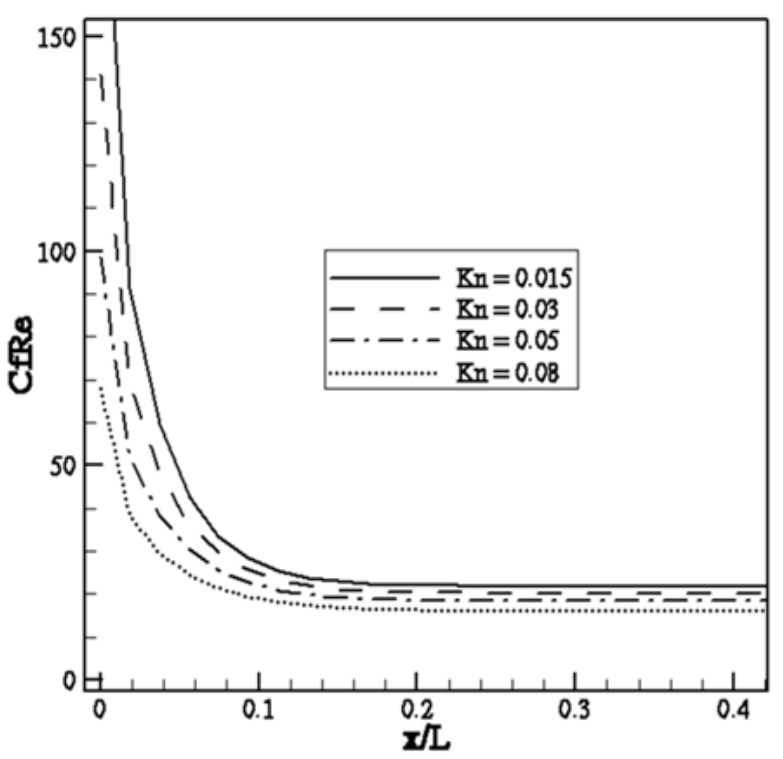

(a)

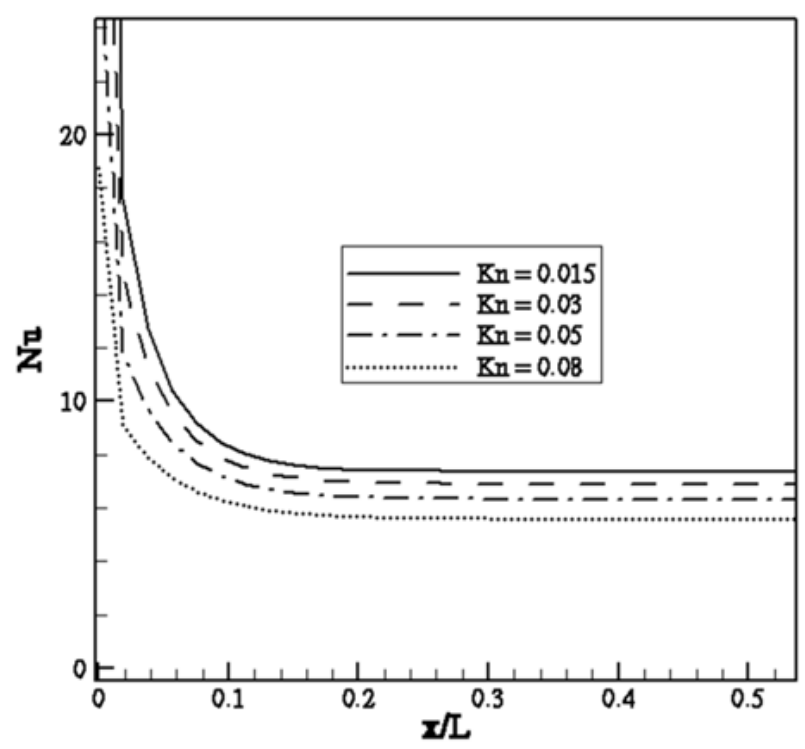

(b)

Fig. 6 Effect of Kn number variation on the skin friction coefficient (a) and the local Nusselt number values (b) along the thermally developing microchannel for $\varphi=0, \operatorname{Pr}=7.06$ at $\operatorname{Re}=3.19$. 


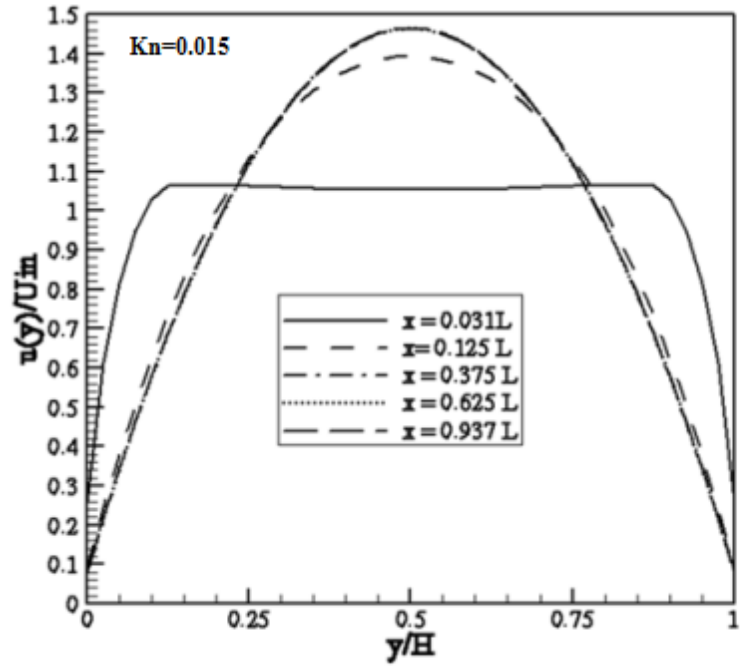

(a)

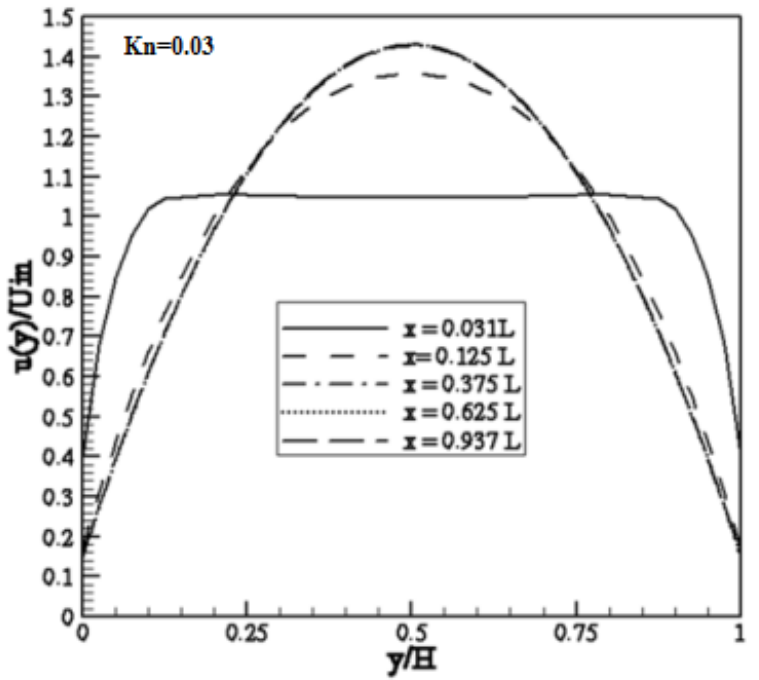

(a)

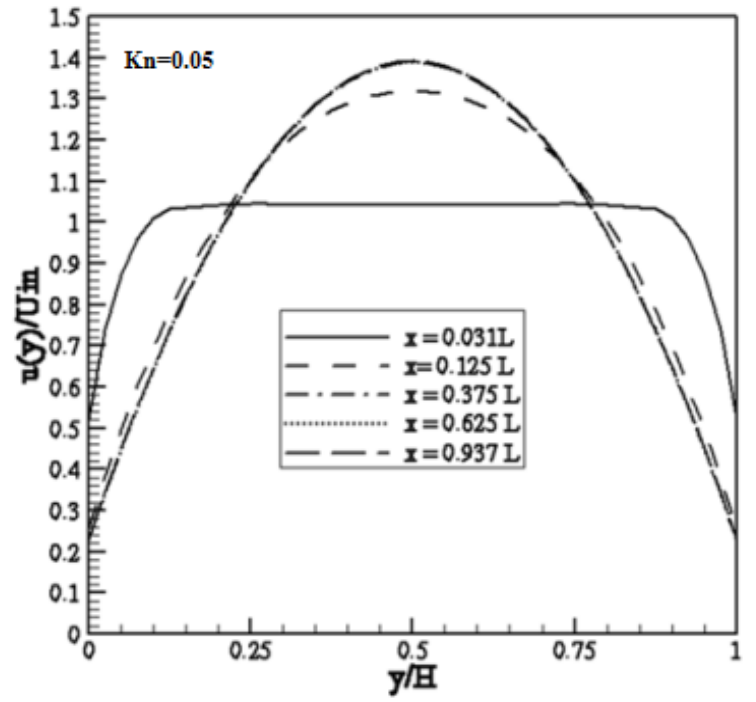

(a)

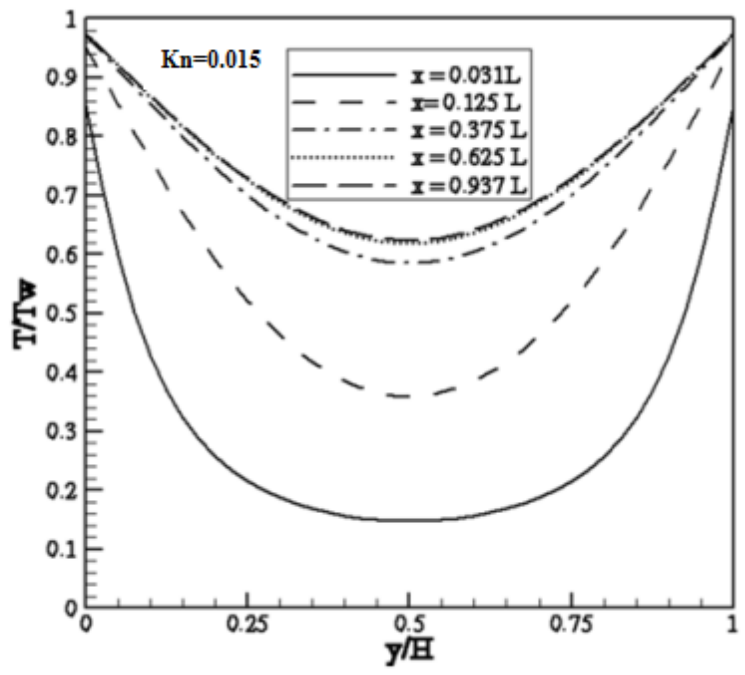

(b)

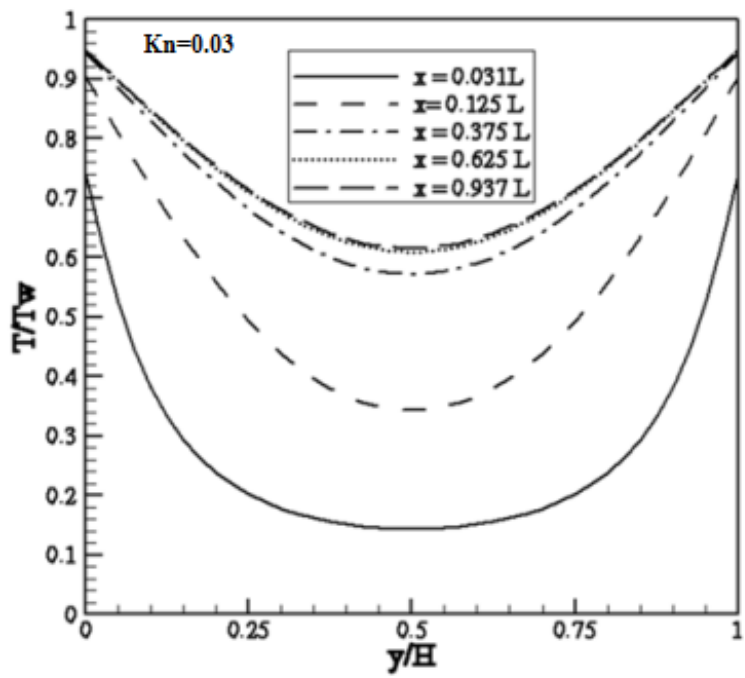

(b)

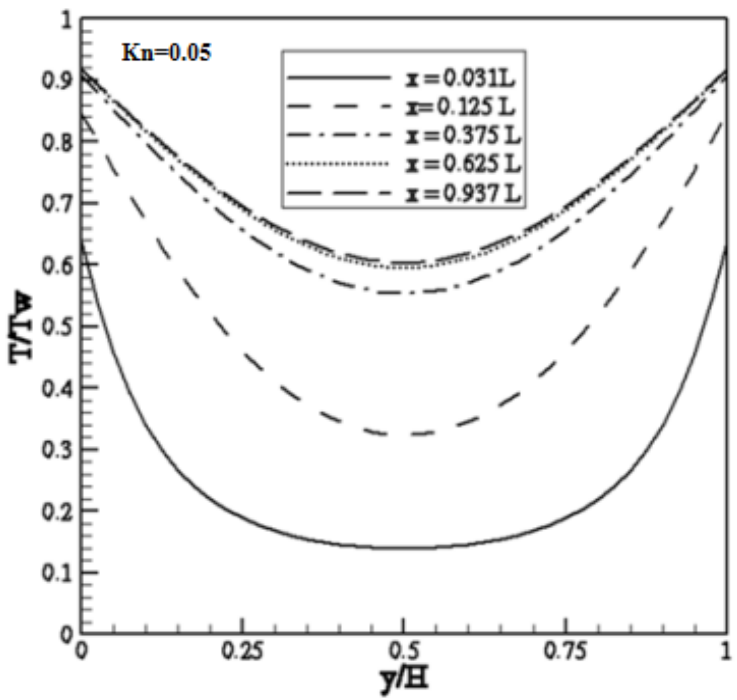

(b)

Fig. 7 Effect of Kn number variation on the velocity (a) and on temperature profiles(b) along the microchannel for $\varphi=0.04$, $\operatorname{Pr}=4.96$ at $\operatorname{Re}=3.19$. 
It can be seen from Fig. 8 that change in nanoparticle volume fractions has a great effect on the temperature jump while for the velocity slip it seems to have no effect on it. Results for local skin friction coefficient CfRe and Nusselt number along the microchannel for different nanoparticle volume fractions and Reynolds number at $\mathrm{Kn}=0.05$ are presented in Fig. 9. Where addition of $2 \%$ or $4 \%$ of Ag nanoparticles leads to improved $\mathrm{Nu}$, without affecting the local skin friction coefficient CfRe, this is due to small variation in the Reynolds number.

Fig. 10 shows the average Nusselt number, for water-Ag nanofluid in different Reynolds number, Knudsen number and nanoparticle volume fractions. According to Fig. 10, the average Nusselt number

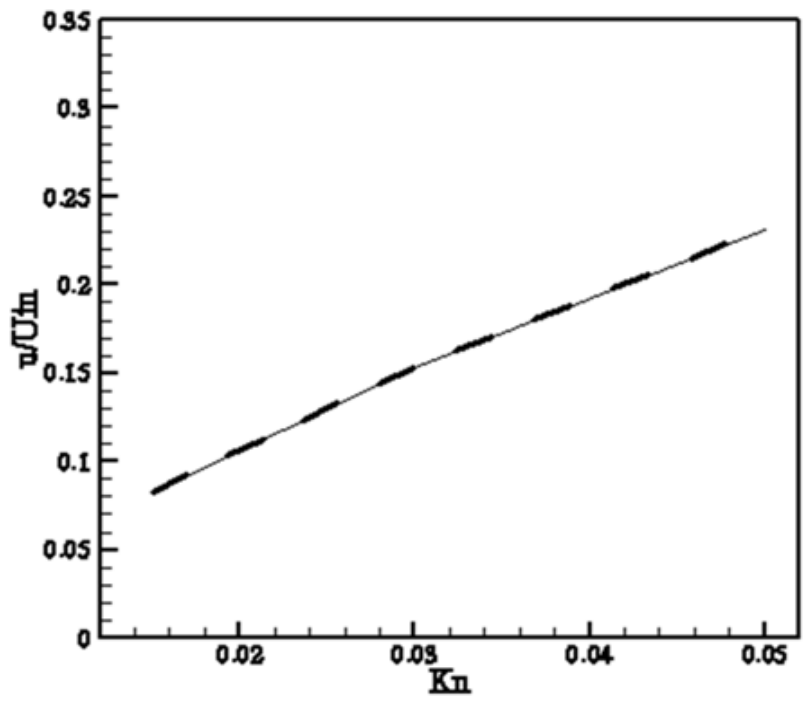

(a) increases, with an increase in Reynolds number and in nanoparticle volume fractions. This is due to great effects of high Reynolds number and higher effective thermal conductivity improvement. The average Nusselt number is increased by $12.3 \%$ at a particle concentration of $4 \%$ compared with that of pure water at $\operatorname{Re}=3.19$. It is also shown that the effect of $\mathrm{Re}$ is especially important at higher volume fractions. However the average Nusselt number decreases with increase in Knudsen number.

Fig. 8 Velocity slip (a) and wall temperature jump (b) variation for various Kn number. Solid lines $\varphi=0, \operatorname{Pr}=7.06$, Dashed lines $\varphi=0.04, \operatorname{Pr}=4.96$ at $\operatorname{Re}=3.19$.

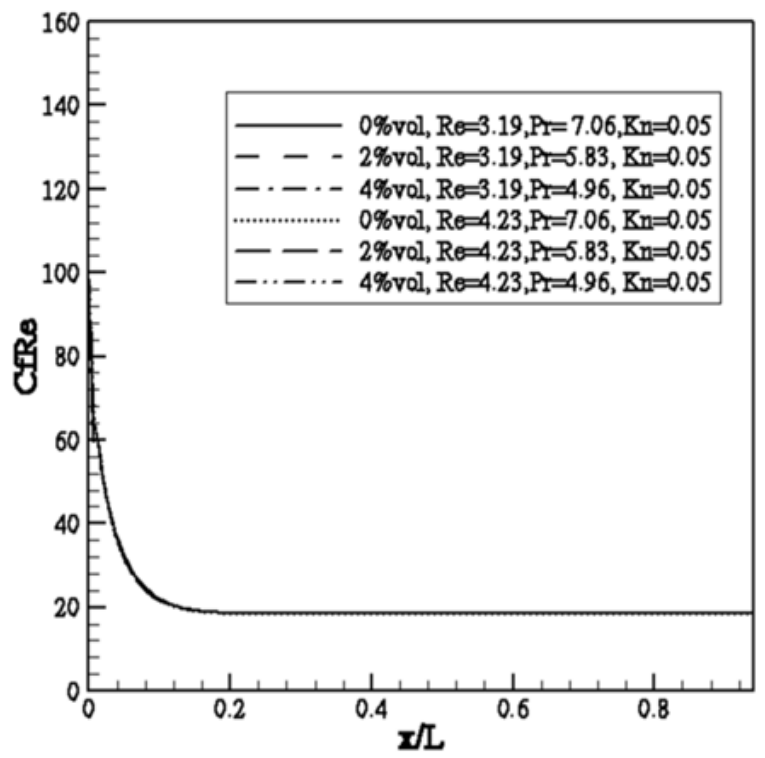

(a)

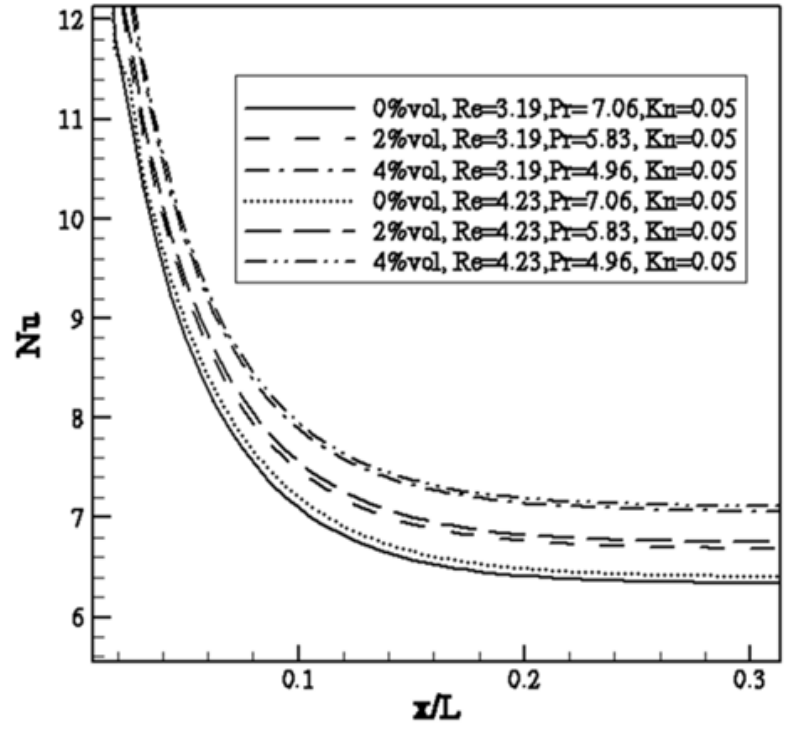

(b)

Fig. 9 Effect of nanoparticle volume fractions and Reynolds number variation on the local skin friction coefficient CfRe (a) and local Nusselt number (b) along the microchannel at $\mathrm{Kn}=0.05$. 


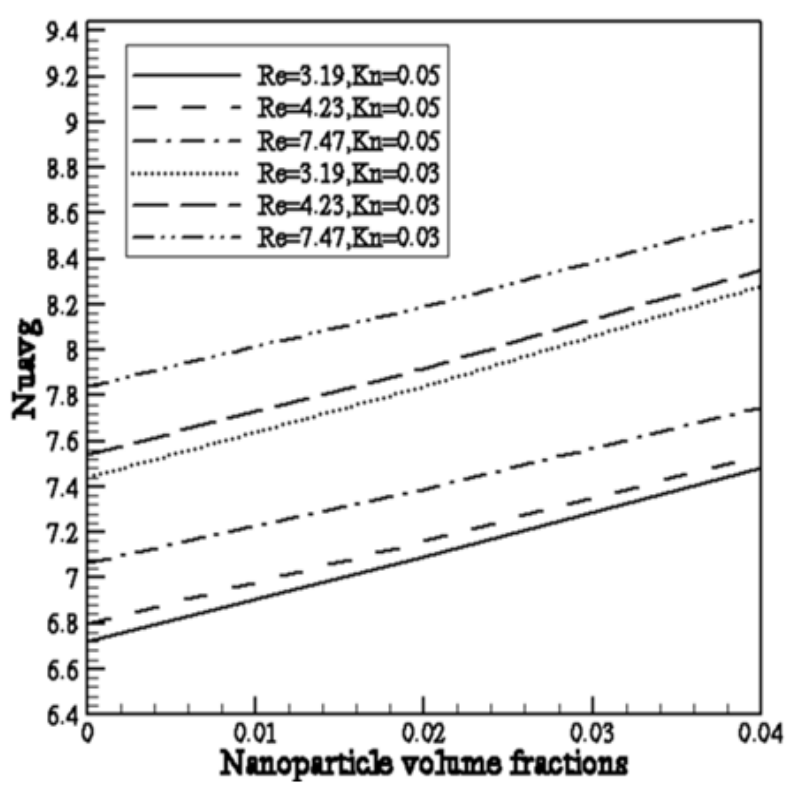

Fig. 10 Effect of nanoparticle volume fractions, Reynolds number and Knudsen number on the average Nusselt number.

\section{CONCLUSIONS}

Nanofluid forced convection heat transfer was studied numerically by adopting the numerical algorithm stream and collide of the lattice Boltzmann method. Analysis of heat transfer enhancement was performed by using (TLBM) model for water-Ag nanofluid flow through the microchannel, the velocity slip and the temperature jump of the wall boundary were adopted. Results showed that using velocity slip and temperature jump boundary conditions strongly affects the whole simulation. It can be seen that increasing Kn number leads to increased slip velocities which causes a decrease in velocity gradient at the wall, and consequently reduces the skin friction coefficient CfRe. However increasing $\mathrm{Kn}$ number leads to a decrease in local Nusselt number values for the thermally developing microchannel. The change in nanoparticle volume fractions did not have significant effect on velocity slip, whereas the temperature jump was more sensitive to it.

It was also shown that, increasing the volume fractions of nanoparticles, leads to an increase in the Nusselt number, without affecting the local skin friction coefficient CfRe. Furthermore, the Nusselt number decreases with increase of the Knudsen number. The average Nusselt number is increased by $12.3 \%$ at a particle concentration of $4 \%$ compared with that of pure water at $\operatorname{Re}=3.19$. And the effect of $\operatorname{Re}$ is especially important at higher volume fractions.

\section{NOMENCLATURE}

$B \quad$ non-dimensional parameter

Cp specific heat $(\mathrm{J} / \mathrm{kg} \cdot \mathrm{K})$

ci microscopic velocity

cs $\quad$ speed of sound

$f \quad$ density-momentum distribution function

$g \quad$ internal energy distribution function

$H, L \quad$ non-dimensional height and length

$K \quad$ thermal conductivity $(\mathrm{W} / \mathrm{m} \cdot \mathrm{K})$

$K n \quad$ Knudsen number

$P \quad$ pressure
Re Reynolds number

$R \quad$ universal constant of gases (J/kg.K)

\section{Greek Symbols}

$\alpha$ thermal diffusivity, $\mathrm{m} 2 / \mathrm{s}$

$\Delta t, \Delta x \quad$ time step and lattice space

$\varepsilon \quad$ internal energy

$\lambda$ mean free path of a molecule

$\mu \quad$ dynamic viscosity, Pa.s

$v \quad$ kinematic viscosity, $\mathrm{m} 2 / \mathrm{s}$

$\rho \quad$ density $(\mathrm{kg} / \mathrm{m} 3)$

$\tau f, \tau g \quad$ momentum and internal energy relaxation times

$\varphi \quad$ volume fraction of nanoparticles

$\omega \quad$ weight factor

$\begin{array}{ll}\text { Super- } & \text { and } \text { Sub-scripts } \\ b & \text { bottom } \\ e q & \text { equilibrium } \\ i & \text { lattice directions } \\ i n & \text { inlet } \\ n e q & \text { non equilibrium } \\ t & \text { top } \\ w & \text { wall }\end{array}$

\section{REFERENCES}

Asproulis, N. and Drikakis, D. 2010, "Boundary slip dependency on surface stiffness", Physical Review E, 81 (6). https://dx.doi.org/10.1103/PhysRevE.81.061503

Buongiorno, J. 2006, "Convective Transport in Nanofluids", Journal of Heat Transfer, 128 (3), 240.

https://dx.doi.org/10.1115/1.2150834

Chai, Z., Lu, J., Shi, B. and Guo, Z. 2011, "Gas slippage effect on the permeability of circular cylinders in a square array", International Journal of Heat and Mass Transfer, 54 (13)-(14), 3009-3014.

https://dx.doi.org/10.1016/j.ijheatmasstransfer.2011.02.049

Chen, S. and Doolen, G.D. 1998, "Lattice Boltzmann method for fluid flows", Annual Review of Fluid Mechanics, 30 (1), 329-364. https:/dx./doi.org/10.1146/annurev.fluid.30.1.329

Chol, S.U.S. 1995, "Enhancing thermal conductivity of fluids with nanoparticles", ASME-Publications-Fed, 231, 99-106.

Docherty, S.Y., Borg, M.K., Lokherby, D.A. and Reese, J.M. 2014, "Multiscale simulation of heat transfer in a rarefied gas", International Journal of Heat and Fluid Flow, 50, 114-125. https:/dx./doi.org/10.1016/j.ijheatfluidflow.2014.06.003

Gad-el-Hak, M. 1999, "The fluid mechanics of microdevices-the Freeman scholar lecture", Journal of Fluids Engineering, 121 (1), 5-33. https:/dx./doi.org/10.1115/1.2822013

Guo, Z., Asinari, P. and Zheng, C. 2009, "Lattice Boltzmann equation for microscale gas flows of binary mixtures", Physical Review E, 79 (2). https://dx.doi.org/10.1103/PhysRevE.79.026702

Kalweit, M. and Drikakis, D. 2008, "Coupling strategies for hybrid molecular-continuum simulation methods", Proceedings of the Institution of Mechanical Engineers, Part C: Journal of Mechanical Engineering Science, 222 (5), 797-806. https:/dx./doi.org/10.1243/09544062JMES716 
Kavehpour, H.P., Faghri, M. and Asako, Y. 1997. "Effects of compressibility and rarefaction on gaseous flows in microchannels", Numerical Heat Transfer, Part A Applications, 32 (7), 677-696. https://dx.doi.org/10.1080/10407789708913912

Khanafer, K., Vafai, K. and Lightstone, M. 2003, "Buoyancy-driven heat transfer enhancement in a two-dimensional enclosure utilizing nanofluids", International Journal of Heat and Mass Transfer, 46 (19), 3639-3653.

http://dx.doi.org/10.1016/S0017-9310(03)00156-X

Kreith, F., Manglik, R.M. and Bohn, M.S. 2011, "Principles of heat transfer", Stamford, Cengage Learning.

Lim, C.Y., Shu, C., Niu, X.D. and Chew,Y.T. 2002, "Application of lattice Boltzmann method to simulate microchannel flows", Physics of Fluids, 14 (7), 2299.

https://dx.doi.org/10.1063/1.1483841

Li, Q., He, Y.L., Tang, G.H. and Tao, W.Q. 2011, "Lattice Boltzmann modeling of microchannel flows in the transition flow regime", Microfluidics and Nanofluidics, 10 (3), 607-618.

https://dx.doi.org/10.1007/s10404-010-0693-1

Mahdy, A. and Chamkha, A. 2015, "Heat transfer and fluid flow of a non-Newtonian nanofluid over an unsteady contracting cylinder employing Buongiorno's model", International Journal of Numerical Methods for Heat \& Fluid Flow, 25 (4), 703-723.

https://dx.doi.org/10.1108/HFF-04-2014-0093

Mohamad, A.A. 2011 Lattice Boltzmann Method. London, Springer London.

Mukherjee, S., Mishra, P.C., Chaudhuri, P. and Banerjee, G. 2018, "Theoretical modeling and optimization of microchannel heat sink cooling with $\mathrm{TiO} 2$-water and $\mathrm{ZnO}$-water nanofluids", International Journal of Heat and Technology, 36 (1), 165-172. https://dx.doi.org/10.18280/ijht.360122

Nie, X., Doolen, G.D. and Chen, S. 2002, "Lattice-Boltzmann simulations of fluid flows in MEMS", Journal of Statistical Physics, 107 (1)-(2), 279-289.

https://dx.doi.org/10.1023/A:1014523007427

Niu, X.D., Shu, C. and Chew, Y.T. 2007, "A thermal lattice Boltzmann model with diffuse scattering boundary condition for micro thermal flows", Computers and Fluids, 36 (2), 273-281. https://dx.doi.org/10.1016/j.compfluid.2005.11.007
Rosa, P., Karayiannis, T.G. and Collins, M.W. 2009, "Single-phase heat transfer in microchannels: The importance of scaling effects". Applied Thermal Engineering, 29 (17)-(18), 3447-3468. https://dx.doi.org/10.1016/j.applthermaleng.2009.05.015

Savithiri, S., Pattamatta, A. and Das, S.K. 2011, "Scaling analysis for the investigation of slip mechanisms in nanofluids", Nanoscale research letters, 6 (1), 471.

https://dx.doi.org/10.1186/1556-276X-6-471

Shen, C., Tian, D.B., Xie, C. and Fan, J. 2004, "Examination of the LBM in simulation of microchannel flow in transition regime", Microscale Thermophysical Engineering, 8 (4), 423-432. https://dx.doi.org/10.1080/10893950490516983

Shokouhmand, H. and Meghdadi Isfahani, A.H. 2011, "An improved thermal lattice Boltzmann model for rarefied gas flows in wide range of Knudsen number", International Communications in Heat and Mass Transfer, 38 (10), 1463-1469.

https://dx.doi.org/10.1016/j.icheatmasstransfer.2011.08.009

Shu, C., Niu, X.D. and Chew, Y.T. 2005, “A Lattice Boltzmann Kinetic Model for Microflow and Heat Transfer", Journal of Statistical Physics, 121 (1)-(2), 239-255. https://dx.doi.org/10.1007/s10955-005-8413-z

Tian, Z.W., Zou, C., Liu, H.J., Guo, Z.L., Liu, Z.H. and Zheng, C.G. 2007, "Lattice Boltzmann scheme for simulating thermal micro-flow", Physica A: Statistical Mechanics and its Applications, 385 (1), 59-68. https://dx.doi.org/10.1016/j.physa.2007.01.021

Zarita, R. and Hachemi, M. 2014, "Microchannel fluid flow and heat transfer by lattice boltzmann method", 4th Micro and Nano Flows Conference, UK London, Brunel university, Sep 7-10, 1-8.

Zhang, Y.H., Qin, R.S., Sun, Y.H., Barber, R.W. and Emerson, D.R. 2005, "Gas Flow in Microchannels - A Lattice Boltzmann Method Approach", Journal of Statistical Physics, 121 (1)-(2), 257-267. https://dx.doi.org/10.1007/s10955-005-8416-9

Zheng, L., Shi, B.C. and Chai, Z.H. 2007, "Lattice Boltzmann method for simulating the temperature jump and velocity slip in microchannels" Communications in Computational Physics, 2, 1125.

Zou, Q. and He, X. 1997, "On pressure and velocity boundary conditions for the lattice Boltzmann BGK model”, Physics of Fluids, 9 (6), 1591-1598

https://dx.doi.org/10.1063/1.869307 